\title{
Abnormal Synaptic Plasticity and Impaired Spatial Cognition in Mice Transgenic for Exon 1 of the Human Huntington's Disease Mutation
}

\author{
Kerry P. S. J. Murphy, ${ }^{1}$ Rebecca J. Carter, ${ }^{1}$ Lisa A. Lione, ${ }^{2,3}$ Laura Mangiarini, ${ }^{5}$ Amarbirpal Mahal, ${ }^{5}$ \\ Gillian P. Bates, ${ }^{5}$ Stephen B. Dunnett, ${ }^{2,4}$ A. Jennifer Morton ${ }^{1}$ \\ ${ }^{1}$ Department of Pharmacology, ${ }^{2}$ Centre for Brain Repair, ${ }^{3}$ Parke-Davis Neuroscience Research, and ${ }^{4}$ Department of \\ Experimental Psychology, University of Cambridge, CB2 1QJ, United Kingdom, and 5 Division of Medical and Molecular \\ Genetics, GKT School of Medicine, Guy's Hospital, London SE1 9RT, United Kingdom
}

Huntington's disease (HD) is an autosomal dominant progressive and fatal neurodegenerative brain disorder caused by an expanded CAG/polyglutamine repeat in the coding region of the gene. Presymptomatic Huntington's disease patients often exhibit cognitive deficits before the onset of classical symptoms. To investigate the possibility that changes in synaptic plasticity might underlie cognitive impairment in HD, we examined hippocampal synaptic plasticity and spatial cognition in a transgenic mouse (R6/2 line) expressing exon 1 of the human Huntington's disease gene containing an expanded CAG repeat. This mouse exhibits a progressive and fatal neurological phenotype that resembles Huntington's disease. We report that $\mathrm{R} 6 / 2$ mice show marked alterations in synaptic plasticity at both CA1 and dentate granule cell synapses, and impaired spatial cognitive performance in the Morris water maze. The changes in hippocampal plasticity were age dependent, appearing at CA1 synapses several weeks before they were observed in the dentate gyrus. Deficits in synaptic plasticity at CA1 synapses occurred before an overt phenotype. This suggests that altered synaptic plasticity contributes to the presymptomatic changes in cognition reported in human carriers of the Huntington' disease gene. The temporal and regional changes in synaptic plasticity within the hippocampus mirror the appearance of neuronal intranuclear inclusions, suggesting a relationship between polyglutamine aggregation and dysfunction.

Key words: Huntington's disease; long-term potentiation; long-term depression; hippocampus; cognition; intranuclear inclusions; NMDA receptor
Huntington's disease (HD) is one of a family of neurodegenerative disorders attributable to an unstable CAG trinucleotide repeat expansion within the open reading frame of the gene (Paulson and Fischbeck, 1996). The age at onset of HD is determined by the length of the CAG repeat expansion (Becher et al., 1998). In humans the symptoms, which usually appear in the third to fifth decades of life, often include an impairment of cognitive function that can eventually lead to dementia (Harper, 1996). The primary sites of neurodegeneration are the striatum and cerebral cortex; however, in later stages of the disease, neuronal cell loss is also evident in other brain regions, including the hippocampus (Vonsattel et al., 1985; Folstein, 1990; Hedreen et al., 1991; Spargo et al., 1993; Utal et al., 1998). There is now considerable evidence that early cognitive impairment can appear in patients before the onset of the classical symptoms (Mohr et al., 1991; Foroud et al., 1995; Lange et al., 1995; Lawrence et al., 1996, 1998). Furthermore, postmortem studies (Vonsattel et al., 1985) suggest that the first symptoms (both motor and cognitive) appear in the absence of overt neuronal cell loss, suggesting that impaired cognition is likely to be caused by a cellular dysfunction rather than a consequence of neuronal cell death.

\footnotetext{
Received Dec. 14, 1999; revised March 22, 2000; accepted March 28, 2000.

We thank M. A. Hickey, T. Humby, M. J. Hunt, and J. P. Spencer for their supporting contributions to this study. We also thank Roger Hart, Wendy Leavens, and Chris Riches for technical assistance.

Correspondence should be addressed to Dr. Kerry P. S. J. Murphy, Department of Biological Sciences, The Open University, Walton Hall, Milton Keynes, UK MK7 6AA. E-mail: k.murphy@open.ac.uk.

Dr. Dunnett's present address: School of Biosciences, Cardiff University, Museum Avenue, Cardiff CK10 3US, UK.

Copyright (C) 2000 Society for Neuroscience $\quad 0270-6474 / 00 / 205115-09 \$ 15.00 / 0$
}

Cognitive processes such as learning and memory are believed to depend on changes in synaptic efficacy in certain key brain regions, including the hippocampus (Bliss and Collingridge, 1993). To assess the importance of hippocampal-dependent forms of learning and synaptic plasticity in HD, we examined spatial cognition and the ability of hippocampal synapses to support both long-term potentiation (LTP) and long-term depression (LTD) in the R6/2 transgenic mouse. These mice express the N-terminal portion of human huntingtin, containing a highly expanded polyglutamine repeat (147-155), and develop a progressive neurological phenotype similar to HD (Mangiarini et al., 1996). At birth, R6/2 mice are indistinguishable from their littermate controls and develop normally until $\sim 8$ weeks of age, at which point an overt phenotype becomes discernible on home cage observation. Early neurological signs include stereotypical hindlimb grooming, dyskinesia, and an irregular gait. These abnormalities slowly become more evident until by 12 weeks all animals are affected. The animals continue to decline further and invariably expire suddenly by $16-18$ weeks of age (the cause of death is unknown). Although an overt phenotype was not commonly seen until 8-9 weeks of age, more stringent motor testing has revealed motor deficiencies from as early as 5-6 weeks (Carter et al., 1999). Similarly, cognitive impairment can also be observed from as early as 3-4 weeks of age (Lione et al., 1999).

\section{MATERIALS AND METHODS}

R6/2 transgenic mice. Mice were taken from a colony established in the Department of Pharmacology, University of Cambridge. The line was maintained by backcrossing to $\mathrm{CBA} \times \mathrm{C} 57 \mathrm{BL} / 6 \mathrm{~F} 1$ animals. The present study used 66 hemizygotic transgenic mice and 72 littermate control mice 


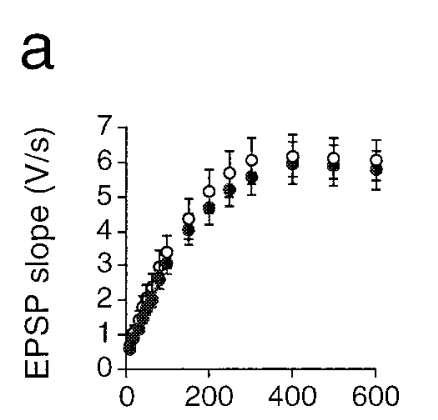

Stimulation Intensity $(\mu \mathrm{A})$

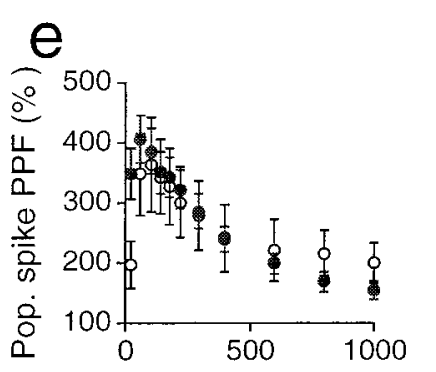

Paired pulse interval (ms)

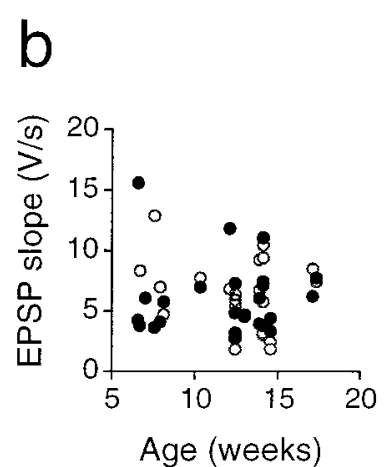

f

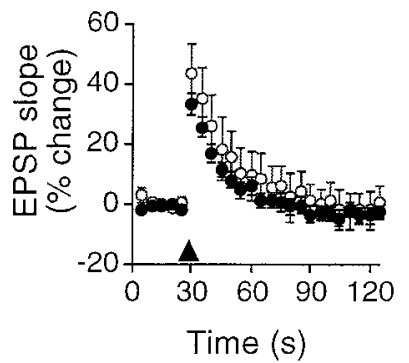

C
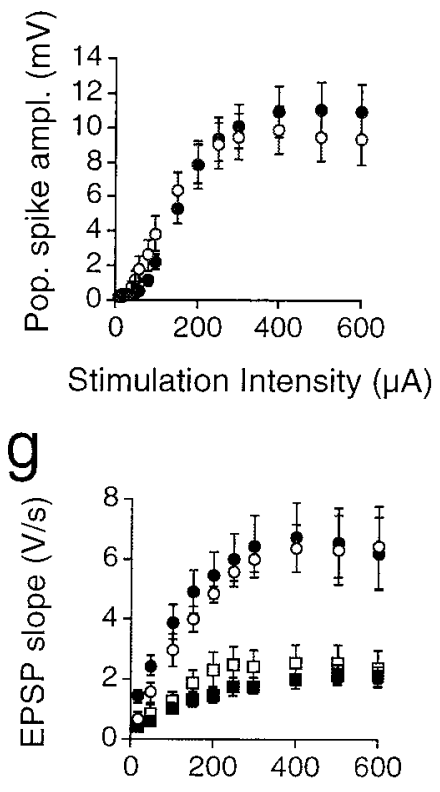

Stimulation Intensity $(\mu \mathrm{A})$

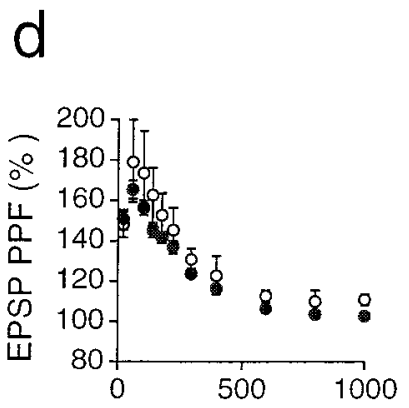

Paired pulse interval (ms)

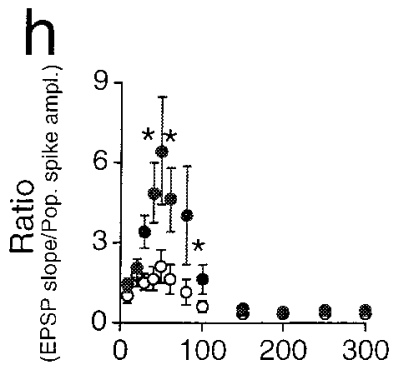

Stimulation Intensity $(\mu \mathrm{A})$

Figure 1. HD mice have near-normal synaptic physiology in area CA1. $a$, Input/output relationships for control and transgenic mice aged 5-18 weeks [control slices denoted by $\bigcirc$ (pooled data from 24 slices, from 17 animals); transgenic slices denoted by (pooled data from 27 slices, from 18 mice)]. Field EPSPs were evoked by stimulation of the Schaffer collateral-commissural pathway at $0.067 \mathrm{~Hz}$ and recorded in the stratum radiatum. $b$, Transgenic synaptic responses are unaffected by age and severity of the phenotype. Individual responses evoked at $400 \mu \mathrm{A}$ are plotted against age [control $\left(r^{2}=\right.$ $0.051, p>0.1)$ and transgenic $\left(r^{2}=0.004, p>0.5\right)$ responses denoted by $\bigcirc$ and $\bullet$, respectively]. $c$, Analysis of the population action potential also revealed a normal input/output curve for transgenic responses. Data points are pooled values from nine control slices (9 animals, aged 5-18 weeks; $\bigcirc$ ) and 13 transgenic slices (from 11 animals, aged 5-18 weeks; $)$ ). Potentials were evoked by stimulation of the Schaffer-commissural pathway and recorded in the stratum pyramidale. $d$, Paired-pulse facilitation of field EPSPs was similar in both control and transgenic slices. The mean slope of the paired EPSP (expressed as percentage change with respect to the first response) is plotted against interpulse interval. Data points are pooled values from nine control slices ( 9 animals, aged 5-18 weeks; $\bigcirc$ ) and 26 transgenic slices (from 17 animals, aged 5-18 weeks; $\bullet$ ). $e$, Paired-pulse facilitation of population action potential. Transgenic responses are enhanced at an interval of $20 \mathrm{msec}(p<0.05)$ but otherwise are normal [9 control slices (from 9 animals aged 5-18 weeks; $\bigcirc$ ) and 22 transgenic slices (from 15 animals, aged 5-18 weeks; $\bullet$ )]. f, PTP is normal in transgenic slices. Experiments were performed in $25 \mu \mathrm{M}$ D-AP5 and responses were evoked at $0.2 \mathrm{~Hz}$. Tetanic stimulation $(3 \times 100$ pulses at $100 \mathrm{~Hz}$; denoted by $\mathbf{\Delta})$ induced a transient potentiation rapidly decaying to baseline within $90 \mathrm{sec}(7$ control slices from 7 animals and 16 transgenic slices from 12 slices, aged 7-14 weeks, denoted by $\bigcirc$ and $\boldsymbol{\bullet}$, respectively). $g$, NMDA receptor-mediated transmission is normal in transgenic mice $\geq 12$ weeks of age. Input/output curves are superimposed for normal synaptic responses (round symbols) and NMDA receptor-mediated potentials (square symbols) recorded in the same afferent pathway [6 control and 6 transgenic slices (open and filled symbols, respectively)]. NMDA receptor potentials were isolated pharmacological in nominally magnesium-free ACSF containing $10 \mu \mathrm{M}$ CNQX. $h$, Analysis of the somatically recorded EPSP and population action potential revealed a decrease in the likelihood for a transgenic EPSP to generate an action potential at lower stimulation intensities. Data points are pooled values of somatic EPSP slope/population action potential ratio plotted against stimulation strength [ 9 control slices ( 9 animals, aged 5-18 weeks; $\bigcirc)$ and 13 transgenic slices (11 animals, aged 5-18 weeks; 0)]. Points indicated by an asterisk are significantly different compared with controls ( $p<0.05$ in each case; Mann-Whitney test). Comparison of the transgenic and control input/output relationships of somatically recorded EPSPs revealed no significant differences between the two groups [slope values $(V / s)$ at 50,100 , and $400 \mu \mathrm{A}$ were $0.72 \pm 0.1,1.85 \pm 0.15,4.59 \pm 0.39$, and $0.79 \pm 0.01(p>0.6), 1.41 \pm 0.24(p>0.1), 4.7 \pm 0.41(p>0.8)$ for transgenic and control slices, respectively].

from the 9 th to the 16th generation. Genotyping was confirmed by PCR (Mangiarini et al., 1996). Blood glucose levels were measured for some animals used in this study.

Hippocampal slice preparation and electrophysiology. Transverse $400 \mu \mathrm{m}$ hippocampal slices were prepared from animals aged between 4 and 18 weeks as described by Murphy and Bliss (1999), maintained in an interface recording chamber, and perfused continuously with oxygenated artificial CSF (ACSF) of the following composition (in mM): $\mathrm{NaCl} 124$, $\mathrm{KCl} 4, \mathrm{NaH}_{2} \mathrm{PO}_{4} 1.25, \mathrm{NaHCO}_{3} 26, \mathrm{CaCl}_{2} 2, \mathrm{MgSO}_{4}$ 2, and D-glucose 10. During the dissection, blood samples were taken from some animals, and blood glucose levels were measured using an automated glucometer (Bayer, Newbury, UK). Initial field recording experiments were performed under blind conditions (see below) and at a temperature of $26^{\circ} \mathrm{C}$. At $26^{\circ} \mathrm{C}$ the metabolic load is reduced [a precaution taken because $\mathrm{HD}$ has been associated with an impairment of energy metabolism; see Jenkins et al. (1993)], thereby maximizing slice survival and viability, especially after the trauma of dissection and slice preparation. All subsequent field experiments were performed at $26^{\circ} \mathrm{C}$. A later series of experiments was performed at the higher temperature of $32^{\circ} \mathrm{C}$. Under these conditions transgenic slices were viable (see Table 1), suggesting that an impairment of energy metabolism may not be readily evident in R6/2 mice.

Field recordings. Two slices prepared from the same hippocampal hemisphere were taken from each animal and transferred to an interface chamber (P. E. Scientific Systems Design, London, UK). Field recordings were made from the cell body layer of one slice to measure the population action potential (population spike) and from the stratum radiatum of the other to measure the field EPSP (fEPSP) using glass microelectrodes filled with $1 \mathrm{M}$ sodium acetate (impedence 2-5 M $\Omega$ ). Potentials were recorded using AC preamplifiers (Neurolog, Welyn Garden City, UK) and stored on a Macintosh computer (using A/Dvance software; R. M. Douglas, Vancouver, Canada). Monopolar tungsten stimulating electrodes (A-M systems, Carlsborg, WA) were placed in the stratum radiatum of each slice to activate Schaffer collateral-commissural fibers. Test shocks were applied at $30 \mathrm{sec}$ intervals, at an intensity that evoked responses that were either $\sim 25 \%$ in LTP or $50 \%$ in LTD of the initial maximum response. Conditioning tetani used to induce LTP at CA1 synapses consisted of three trains of 100 shocks at $100 \mathrm{~Hz}$ with an 
Table 1. Comparison of CA1 pyramidal cell intrinsic membrane properties

\begin{tabular}{lrrr} 
& $\begin{array}{l}\text { Control }(n=14 \text { cells from } \\
11 \text { mice })\end{array}$ & $\begin{array}{l}\text { Transgenic }(n=12 \text { cells } \\
\text { from } 7 \text { mice })\end{array}$ & NS \\
\hline$E_{\mathrm{m}}(\mathrm{mV})$ & $-69.0 \pm 1.0$ & $-67.3 \pm 1.7$ & $\mathrm{NS}$ \\
$R_{\mathrm{in}}(\mathrm{M} \Omega)$ & $31.3 \pm 2.5$ & $34.6 \pm 2.6$ & $\mathrm{NS}$ \\
Threshold $(\mathrm{mV})$ & $-56.9 \pm 0.8$ & $-55.6 \pm 1.0$ & $p<0.05^{a}$ \\
Action potential ${ }^{a}(\mathrm{mV})$ & $82.4 \pm 2.7$ & $73.2 \pm 2.8$ & $\mathrm{NS}$ \\
A.P. half-width $(\mathrm{msec})$ & $1.04 \pm 0.03$ & $0.91 \pm 0.06$ & \\
\hline
\end{tabular}

All cells recorded in slices prepared from mice $>12$ weeks of age. $E_{\mathrm{m}}$, Resting membrane potential; $R_{\mathrm{in}}$, input resistance calculated from steady-state voltage deflection produced by intracellular injection of hyperpolarizing current $(-0.2$ or -0.4 $\mathrm{nA}$ for $150 \mathrm{msec}$ ). Threshold, membrane potential at which an action potential was initiated.

${ }^{a}$ Action potential amplitude measured from firing threshold.

intertrain interval of $10 \mathrm{sec}$ (Nosten-Bertrand et al., 1996). LTD or depotentiation were induced by application of 900 shocks at $1 \mathrm{~Hz}$ (Dudek and Bear, 1992). For slices of the dentate gyrus, the bathing medium contained $4 \mathrm{mM} \mathrm{Ca}^{2+}$ and $\mathrm{Mg}^{2+}$ and $100 \mu \mathrm{M}$ picrotoxin (Hanse and Gustafsson, 1992). To induce LTP, the medial perforant path was stimulated with two trains of 20 pulses at $100 \mathrm{~Hz}$, with a $30 \mathrm{sec}$ interval at twice test shock duration (Nosten-Bertrand et al., 1996). Test shocks were set to the threshold of the population action potential, and field recordings were made in the molecular layer. NMDA receptor-mediated potentials were isolated pharmacologically using $\mathrm{Mg}^{2+}$-free ACSF containing $10 \mu \mathrm{M}$ 6-cyano-7-nitroquinoxaline-2,3-dione disodium (CNQX; Tocris, Bristol, UK). In all cases, application of the NMDA receptor antagonist D-(-)-2-amino-5-phosphonopentanoic acid (AP5; Tocris) abolished the synaptic potential.

Intracellular experiments. Intracellular recordings were made from CA1 pyramidal cells as described by Murphy et al. (1994) and maintained at $32^{\circ} \mathrm{C}$. Briefly, cells were impaled with microelectrodes filled with $3 \mathrm{M}$ potassium acetate or potassium chloride (impedence 70-100 $\mathrm{M} \Omega$ ), and membrane potentials were recorded using an Axoclamp 2B amplifier (Axon Instruments, Foster City CA). Only those cells that exhibited a stable resting membrane potential more than $-60 \mathrm{mV}$ over a $20 \mathrm{~min}$ period in the absence of holding current were included in this study. Input resistances were calculated by injection of hyperpolarizing current (square pulse, $150 \mathrm{msec}$ duration, typically $0.2-0.4 \mathrm{nA}$ ), and action potentials were evoked by the injection of depolarizing current.

Up until 10 weeks of age, all experiments were performed blind. All animals killed before 12 weeks of age were genotyped postmortem. Animals aged $>12$ weeks were identified by phenotype. Approximately equal numbers of male and female mice were used in this study.

Unless stated otherwise, the significance of differences between groups produced by conditioning stimuli was assessed by unpaired two-tailed Student's $t$ tests. All mean values are expressed as mean \pm SEM.

Morris water maze. Thirty-one female mice aged 7 weeks of age were tested by a blinded experimenter at the same time each day using standard protocols as described by Stewart and Morris (1993). Briefly, mice were trained in the water maze (diameter $100 \mathrm{~cm}$, height $40 \mathrm{~cm}$, water depth $25 \mathrm{~cm}$ ) over a $10 \mathrm{~d}$ period, receiving four trials per day. The submerged platform (diameter $11.5 \mathrm{~cm}$, height $24.5 \mathrm{~cm}$ ) was placed at a fixed location within the northeast quadrant. Each trial was separated by 5-10 min. A mouse was placed in the bath facing the wall of the pool at one of four randomly chosen starting positions (north, east, south, west). The mouse was allowed to swim until it located and climbed onto the submerged platform. If the mouse failed to locate the platform within 60 sec, it was removed from the water and placed on the platform. At the end of each trial, mice were left on the platform for $15 \mathrm{sec}$. The latency to escape the water was recorded for each trial. On day 10, the mice received a single probe test $5-10 \mathrm{~min}$ after the last trial. Before the probe test the platform was removed from the bath. The swim path of each mouse was recorded over $60 \mathrm{sec}$ while it searched for the missing platform. The distance swum and time spent in each quadrant of the maze, as well as the total path length, were traced and measured from video recordings. Animals were identified by genotyping. Unless stated otherwise, statistical comparisons were undertaken by two-factor ANOVA.

Immunocytochemistry. Brains were prepared as described by Reynolds et al. (1998). Briefly, brains were dissected, frozen rapidly on powdered dry ice, and stored at $-80^{\circ} \mathrm{C}$. Brains were then cryosectioned $(30 \mu \mathrm{m})$, and inclusions were visualized by staining for ubiquitin using a rabbit polyclonal anti-ubiquitin antibody (1:2000; DAKO, Ely, UK). A horseradish peroxidase-conjugated secondary antibody (1:1000; Vector Laboratories, Peterborough, UK) was used, and staining was visualized using diaminobenzidine (Sigma, Poole, UK).

\section{RESULTS}

\section{Synaptic properties and plasticity at CA1 synapses}

Initial experiments were designed to examine the basal properties of synaptic function in area CA1 of the hippocampus. Analysis of synaptic transmission revealed little difference between transgenic and control animals, regardless of the severity of the phenotype. Stimulation intensity was set to elicit responses $\sim 25 \%$ of the maximum. Input/output curves for transmission at transgenic and control CA1 synapses were indistinguishable (Fig. 1a-c). Paired-pulse stimulation, a test of presynaptic function, also revealed little difference between transgenic and control mice (Fig. $1 d, e)$, suggesting that normal synaptic transmission occurs in transgenic mice and that slice viability is not affected by the transgene or the severity of the phenotype. Indeed, the apparent near-normality of the slices, even when prepared from animals in the terminal phase of the phenotype (12-18 weeks of age), was demonstrated by a series of intracellular recordings made in transgenic CA1 neurons. These cells had normal resting potentials, input resistances, and firing thresholds (Table 1). However, the mean amplitude of the action potential was significantly smaller than that for control cells.

We next investigated synaptic plasticity at CA1 synapses using a high-frequency conditioning tetanus $(3 \times 100$ pulses at $100 \mathrm{~Hz})$ and a low-frequency conditioning tetanus (900 pulses at $1 \mathrm{~Hz}$ ) to induce LTP and LTD, respectively. Baseline responses were monitored for 10-30 min before conditioning and were found to be stable. Tetanic conditioning revealed a marked difference in the ability of transgenic slices to support LTP, with potentiation of the EPSP being significantly reduced in transgenic slices $(p<$ 0.001) (Fig. 2a). Interestingly, LTP of the population action potential was normal (Fig. $2 b$ ). However, low-frequency conditioning applied $1 \mathrm{hr}$ after the induction of LTP resulted in depression (depotentiation) of both transgenic field EPSPs and population action potentials, whereas the control responses showed only a transient depression that recovered to the potentiated baseline (Fig. 2a,b). Furthermore, low-frequency conditioning of naive transgenic slices induced LTD in both the EPSP and population action potential but failed to do so in control slices (Fig. $2 c, d$ ). The LTD was homosynaptic (second pathway not shown) and was not attributable to afferent damage, because a subsequent period of tetanic conditioning induced LTP (Fig. 2c). The changes in synaptic plasticity at transgenic CA1 synapses was 
a
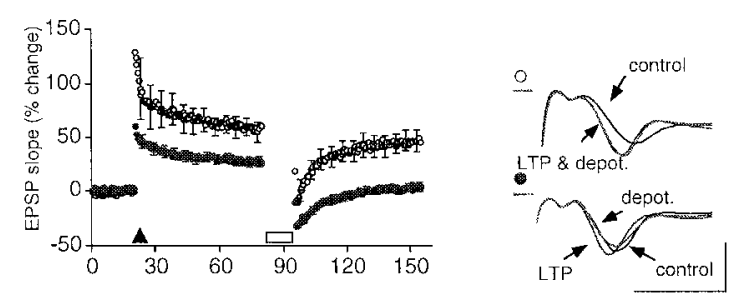

b

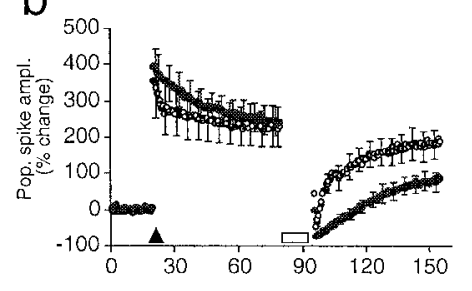

C

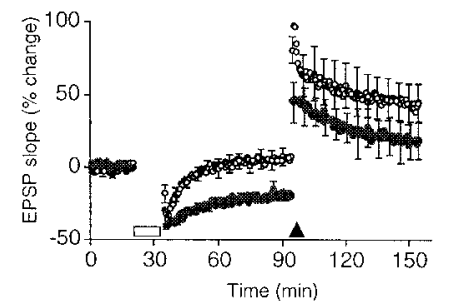

d
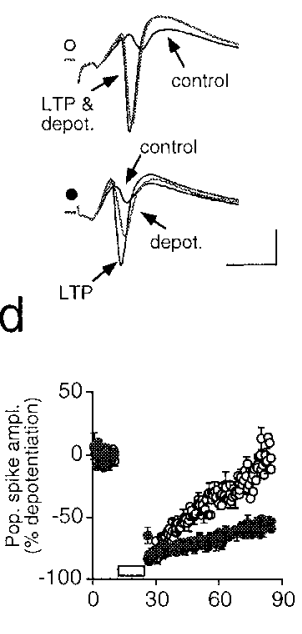

Figure 2. HD mice express abnormal synaptic plasticity at CA1 synapses. a, Left, Transgenic synapses show reduced LTP and exhibit activity-dependent synaptic depression (depotentiation) of the field EPSP. EPSP slope is plotted as percentage change against time and expressed as a pooled mean [13 control slices $(\bigcirc)$ from 12 animals, and 17 transgenic slices (๑) from 15 animals; aged 5-18 weeks]; SEM was plotted for every fifth datum. Tetanic stimulation (denoted by $\mathbf{A}$ ) induced robust LTP $(56.5 \pm 6.6 \%$; measured $1 \mathrm{hr}$ after induction over $5 \mathrm{~min})$ in control slices but a smaller LTP at transgenic synapses $(26.8 \pm 3.4 \% ; p<0.001$, Welch $t$ test). In contrast, low-frequency conditioning applied $1 \mathrm{hr}$ after the induction of LTP failed to depotentiate the control slices $(-4.9 \pm$ $1.7 \%$; measured $1 \mathrm{hr}$ after conditioning) but induced depression at transgenic synapses $(-18.5 \pm 2.8 \% ; p<0.001)$. Right, Representative traces showing averages of five consecutive EPSPs taken immediately before tetanic stimulation (indicated as control), $1 \mathrm{hr}$ after the tetanus (indicated as $L T P$ ), and $1 \mathrm{hr}$ after low-frequency stimulation (indicated as depot.) are superimposed. $b$, Transgenic slices exhibit normal LTP of the population action potential but show marked depotentiation. Left, Tetanic conditioning induced LTP of similar magnitude in control $(\bigcirc)$ and transgenic $(\bullet)$ slices [229.7 $\pm 36.6 \%$ (15 slices from 13 animals) and $246.1 \pm 38.3 \%$ (18 slices from 17 animals), respectively; aged 5-18 weeks; $p=0.76]$. The mean population action potential amplitudes were similar for control and transgenic slices before conditioning $(2.23 \pm 0.29 \mathrm{mV}$ and $2.52 \pm 0.29 \mathrm{mV}$ for control and transgenic slices, respectively; $p>0.4)$ and $1 \mathrm{hr}$ later $(6.79 \pm 1.05$ and $8.06 \pm 0.94 \mathrm{mV}$ for control and transgenic slices, respectively; $p>0.3$ ). Low-frequency conditioning applied $1 \mathrm{hr}$ later failed to depotentiate control responses $(-7.0 \pm 2.9 \%)$ but induced a profound depression in the transgenic potential $(-46.9 \pm 3.9 \% ; p<0.001)$. Right, Representative traces showing averages of five consecutive population action potentials taken immediately before tetanic stimulation, $1 \mathrm{hr}$ after the LTP, and low-frequency stimulation are superimposed and indicated as in $a . c$, LTD is only seen in transgenic slices. Low-frequency stimulation (bar) induced LTD in transgenic (๑) EPSPs but not in control $(\bigcirc)$ responses $(-19.2 \pm 1.2 \%, 7$ slices, and $6.34 \pm 4.9 \%, 5$ slices, respectively;

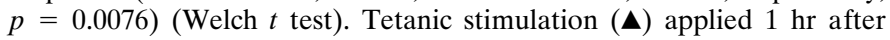
low-frequency conditioning successfully induced LTP in both control and transgenic slices. Note that for experiments in $c$ and $d$, the test shock was set to elicit responses at $50 \%$ of maximum. $d$, Low-frequency conditioning (bar) also selectively induces LTD of transgenic population action potentials $[-56.2 \pm 4.1 \%(n=7)$ and $3.7 \pm 13.7 \%(n=6)$ for transgenic $(\bullet)$ and control $(\bigcirc)$ slices, respectively; $p=0.0087$ (Welch $t$ test)]. Calibration $(a, b): 5 \mathrm{msec}, 5 \mathrm{mV}$. seen in all mice aged 5-18 weeks and did not appear to be affected by the severity of the phenotype (see Fig. $6 a$ ).

It was noted that post-tetanic potentiation (PTP) of the EPSP was smaller in transgenic slices (Fig. 2a). PTP is believed to be an indication of presynaptic function, reflecting a period of enhanced transmitter release caused by the loading of the presynaptic terminal with calcium ions during tetanic conditioning. It is possible that the impairment in LTP of the transgenic EPSP is caused by a reduction in transmitter release that is only apparent during a period of intense synaptic activity such as that seen during tetanic stimulation. To investigate this possibility further, tetanic conditioning was applied to control and transgenic slices in which the LTP inductive mechanism was blocked by the NMDA receptor antagonist D-AP5 (Collingridge et al., 1983). Under these conditions, the degree of PTP was similar for controls and transgenic EPSPs (Fig. 1f), suggesting that impaired transmitter release during the tetanus was not responsible for the failure in LTP.

An alternative explanation for the differences in LTP and PTP might be modification of NMDA receptor function (Collingridge et al., 1983; Bliss and Collingridge, 1993; Cochilla and Alford, 1999). However, examination of NMDA receptor-mediated field potentials in slices prepared from animals older than 12 weeks revealed no apparent differences in NMDA receptor function (Fig. 1g). It is conceivable that molecular events downstream of the NMDA receptor, such as postsynaptic intracellular signaling and/or retrograde messenger generation, are dysfunctional in the R6/2 mouse and account for the abnormal change in PTP seen when NMDA receptors are operative. In rat, the induction of LTD in slices prepared from young animals ( $<4$ weeks) is sensitive to the blockade of NMDA receptors (Dudek and Bear, 1992). We found that AP5 completely blocked the induction of LTD in transgenic slices (see Fig. $6 c$ ). These data suggest that NMDA receptor function is normal but that biochemical cascades associated with them may be dysfunctional.

The observation that transgenic cells exhibited a reduced action potential during somatic depolarization does not accord with the finding that the input/output relationship for the transgenic population action potential was normal (Fig. 1c). However, closer investigation of synaptically generated population action potentials revealed a marked difference between transgenic and control slices. Figure $1 h$ shows the ratio of the somatically recorded field EPSP and population action potential against stimulation. At lower stimulation intensities, a transgenic EPSP is less likely to generate an action potential than control potentials. Alternatively, it is possible that the cells firing are those with smaller action potentials. It is possible that this stimulus-dependent effect on EPSP/action potential coupling might account for the difference seen in LTP at the level of the transgenic EPSP and population action potential (see Discussion).

\section{Spatial cognition}

We would expect dysfunctional synaptic plasticity in the hippocampus to affect hippocampal-dependent forms of learning such as spatial cognition (Morris et al., 1986, 1998; Chapman et al., 1999). To address this possibility, 7-week-old animals were tested in a modified Morris water maze (Stewart and Morris, 1993). Control mice rapidly learned the location of a submerged platform, whereas transgenic mice performed poorly (Fig. 3a) $(p<0.001)$. After training, the platform was removed, and a probe test was performed to examine the exploratory behavior of the mice. Unlike control mice that repeatedly returned to the 


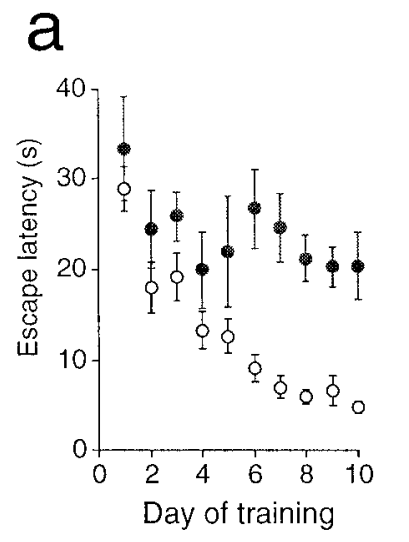

b

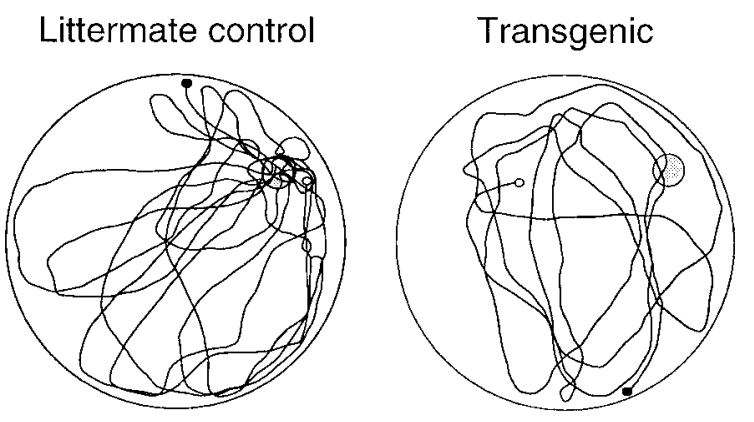

Figure 3. Spatial cognition is impaired in HD mice. $a$, Mean escape latency is plotted against day of training in the Morris water maze, commencing at 7 weeks of age [ 22 control $(\bigcirc)$ and 9 transgenic $(O)$ mice]. Mice did not differ in initial escape latency, indicating that transgenic mice did not exhibit a nonspecific sensory or motor impairment. Over the course of training, control mice rapidly learned the location of the submerged platform, whereas transgenic mice showed little improvement (ANOVA genotype $\times$ day interaction $F_{(9,261)}=2.45, p<0.02$ ). $b$, Representative swim paths illustrate the impairment of spatial cognition during the probe trial in transgenic mice. Although the controls concentrated their search in the location at which the platform had been placed during training, the transgenic mice showed less focused swim paths. $c$, Probe test analysis reveals that transgenic ( filled bar) mice spend less time in the platform quadrant than controls (open bar; $p<0.02$ using two-tailed $t$ test to compare time spent in platform quadrant).

location of the platform, the transgenic animals swam in a random manner, with little or no reference to the location of the platform (Fig. 3b). Probe test analysis revealed that the transgenic mice spent less time than control mice in the quadrant that had previously contained the submerged platform (Fig. 3c) $(p<0.05)$. Although transgenic mice exhibited a motor swimming deficit in that they swam more slowly than controls, the comparison of swim paths taken (illustrated in Fig. $3 b$ ) demonstrated that transgenic mice were cognitively impaired. Recent analysis of younger mice with less developed motor impairment also demonstrated a clear cognitive deficit in the water maze (Lione et al., 1999).

\section{Intranuclear inclusions and synaptic plasticity}

A hallmark of HD is the appearance of highly ubiquitinated neuronal intranuclear inclusions (NIIs) (Fig. 4). These were first described in the R6/2 mouse (Davies et al., 1997) and then later found in human postmortem HD brain (DiFiglia et al., 1997). In $\mathrm{HD}$, NIIs are insoluble proteinacious aggregates that include the N-terminal fragment of mutant huntingtin containing the expanded polyglutamine repeat (Davies et al., 1997). Furthermore,
NIIs now appear to be a common feature in most triplet repeat disorders (Perutz, 1999). Although NIIs have been reported previously in the hippocampus of R6/2 mice (Davies et al., 1997; Ono et al., 1999), they have not been described in any detail. We report here that the appearance of NIIs in the hippocampal formation of the R6/2 mouse is age dependent and shows a marked regional distribution. Inclusions were present in the principal cells of the CA1 region by 3 weeks of age (Fig. $5 a, b, e, f$ ), several weeks before the onset of phenotypic behavior or the appearance of NIIs in other hippocampal areas. In the dentate gyrus (Fig. $5 c, d, g, h$ ), inclusions are present at 7 weeks but are not present in all neurons in the stratum granulosum until $\sim 10$ weeks of age.

The role of NIIs in either the pathogenesis of HD or the decline in the R6/2 mouse is not understood. However, the temporal separation of the appearance of NIIs in the CA1 subfield and their appearance in the granule cells of the dentate gyrus provided an opportunity to compare synaptic plasticity in the presence and absence of NIIs in animals of a similar age and phenotypic status. Experiments were performed to assess LTP at perforant path-granule cell synapses in one group of animals aged between 4-7 weeks and a second group aged 12 weeks or more (time periods corresponding with low or widespread expression of NIIs in the stratum granulosum, respectively). PTP was normal in the 4-7 week group and LTP was not significantly impaired $(p=0.09)$, whereas the older transgenic mice $(\geq 12$ weeks) expressed dramatically reduced LTP $(p<0.01)$ (Fig. 6b). In contrast, LTP and LTD at transgenic CA1 synapses were significantly reduced at 5 weeks of age $(p<0.05$ and $p<0.01$, respectively) (Fig. $6 a$ ). Together, these observations suggest that the temporal and regional pattern of altered plasticity within the hippocampus of R6/2 mice may be related to the appearance and distribution of NIIs.

\section{DISCUSSION}

We report that in a progressive transgenic model for HD, both synaptic plasticity and spatial cognition are impaired at a time point before the onset of an overt phenotype. The synaptic dysfunction is a selective impairment of LTP coupled with activity-dependent depression of synaptic transmission. These changes occur before the onset of neuronal cell loss in the R6/2 mouse [which has been reported to be detectable in several brain regions from 13 weeks of age (Davies et al., 1999)]. Based on this evidence, we propose that altered synaptic plasticity may contribute to the early cognitive deficit seen in presymptomatic HD patients. Impaired LTP and cognitive dysfunction have been reported in transgenic models of Alzheimer's disease (Nalbantogluet et al., 1997; Chapman et al., 1999). In one study, although LTP was impaired, LTD was not abnormal (Nalbantogluet et al., 1997). Interestingly, in the R6/2 mouse, the conspicuous change in activity-dependent plasticity is one of synaptic depression. Given that LTP was normal at the level of the population action potential (Fig. $2 b$ ), and that LTP of the EPSP could be recovered if a stronger stimulation intensity was used (Fig. 2c), it is tempting to suggest that, at least in part, the cognitive deficit seen in the $\mathrm{R} 6 / 2$ mouse is attributable to abnormal synaptic depression. If this is indeed the case, then this is the first time that LTD has been implicated in cognitive dysfunction.

The finding that there is weakened coupling between the EPSP and generation of action potentials in the R6/2 mouse was unexpected. Furthermore, the observation that in older transgenic mice the action potential was reduced in a subset of cells suggests 
Figure 4. Photomicrographs of ubiquitinated NIIs in CA1 neurons in a section of R6/2 mouse brain (13 weeks of age) under bright-field $(a, b)$ or fluorescence $(c, d)$ illumination. The areas outlined in $a$ and $c$ are shown at higher magnification in $b$ and $d$. Inclusions were immunostained for ubiquitin, and the section was counterstained with the fluorescent dye Hoechst 33258 to visualize nuclei. Small arrows in $b$ and $d$ show that the same inclusions can be seen in both fields. Numerous neuronal nuclei can be seen in the pyramidal cell layer $(c)$. At higher magnification, inclusions can be seen clearly localized to the nucleus of CA1 neurons. The large arrow in $b$ and $d$ indicates an inclusion in a nucleus stained with Hoechst dye (arrowheads). Scale bar (shown in $a$ ): $a, c$, $100 \mu \mathrm{m} ; b, d, 33 \mu \mathrm{m}$.
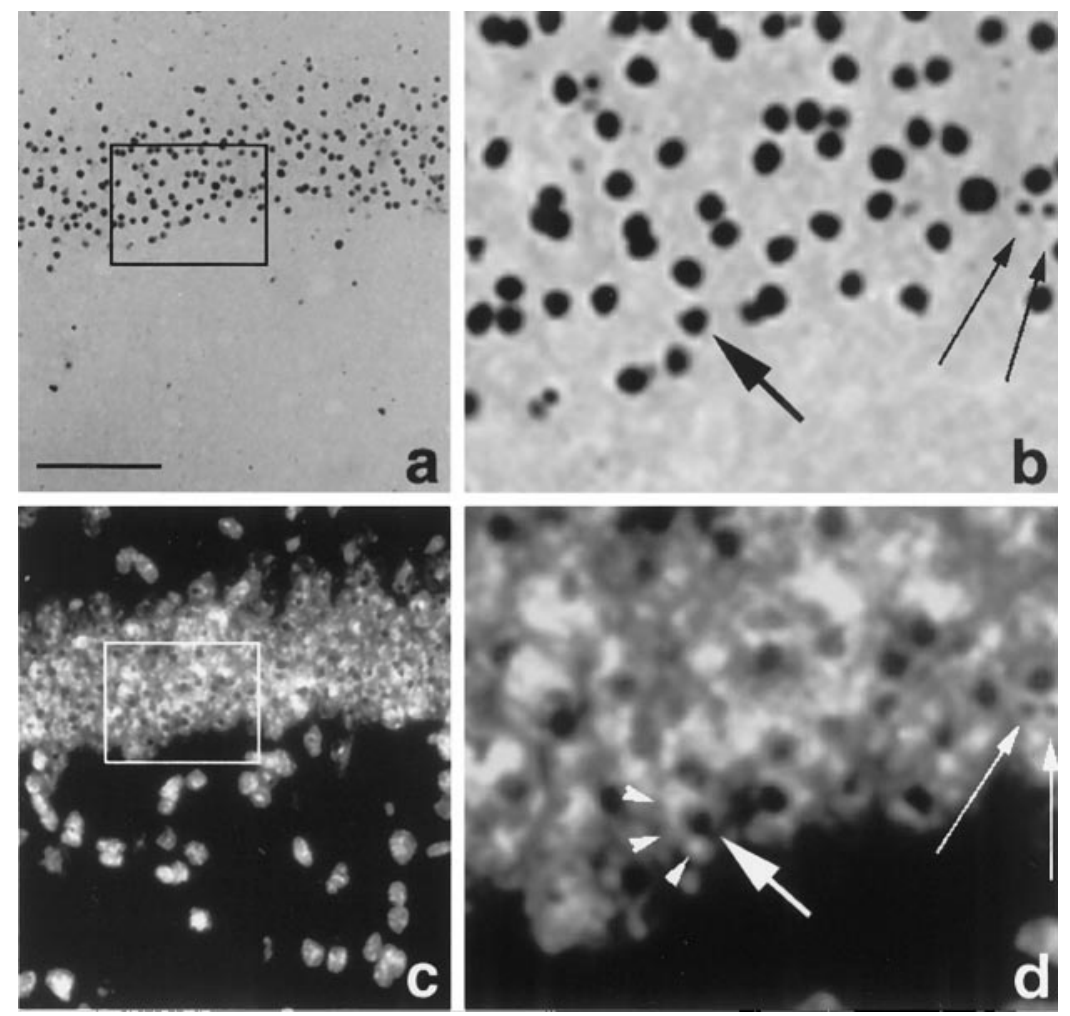

that the mechanisms underlying the generation of action potentials requires further investigation. The reduced population action potential at lower stimulation intensities might account for the differences seen in LTP expressed at the level of the dendritic EPSP and the somatic action potential. However, it should be noted that experiments using a sodium channel antagonist to block the propagation of action potentials still expressed normal LTP (Gustafsson et al., 1987). The dissociation between the EPSP and action potential may have a profound effect on the passage of information through polysynaptic neural circuits; it is tempting to suggest that this might be a factor underlying the neurological and motor deficits seen in the R6/2 mouse. Recently, a similar reduction in action potential amplitude has been reported in R6/2 striatal neurons (Levine et al., 1999). However, these cells also showed marked changes in resting membrane potential and input resistance, phenomena absent in CA1 hippocampal neurons reported here.

In all other respects, basal transmission at CA1 synapses appears to be normal. This contrasts markedly with changes reported in two other mouse lines expressing a mutated murine HD gene (Hdh mouse) (Shelbourne et al., 1999; Usdin et al., 1999) or a yeast artificial chromosome (YAC) expressing mutant fulllength human huntingtin (YAC mouse) (Hodgson et al., 1999). Unlike the R6/2 mouse, the $H d h$ mutant shows abnormalities in both PPF and PTP, whereas the YAC mutant exhibits NMDA receptor-mediated hyperexcitability. In agreement with our study, both of these models also show an impairment of LTP at CA1 synapses. Based on the deficit in PTP and a reduced rate of MK801 binding to NMDA receptors, it was suggested that a frequency-dependent deficit in transmitter release might underlie the abnormalities in synaptic function seen in the Hdh mutant. Indeed, normal huntingtin has been associated with vesicle trafficking and is known to be enriched at the presynaptic terminal (DiFiglia et al., 1995; Gutekunst et al., 1995; Sharp et al., 1995).
We also saw a decrease in PTP under conditions similar to those used in the $H d h$ mutant study. However, when the experiment was repeated in the presence of an NMDA receptor antagonist, PTP was normal. It is therefore possible that the changes in PTP and MK801 binding in the $H d h$ mutant are not a direct consequence of dysfunctional transmitter release but attributable to a modification in NMDA receptor-mediated function (Chen et al., 1999) or possibly other glutamate receptors such as metabotropic receptors (Cha et al., 1998).

The changes in synaptic function reported in the $Y A C$ mouse study are difficult to reconcile with our finding: first, because of the different mouse strain used, and second, because their experiments were performed in the absence of extracellular magnesium. Interestingly, unlike the R6/2 mouse, the $Y A C$ mouse exhibited a marked increase in basal transmission mediated by NMDA receptors. Recently, it has been shown that injection of full-length mutated huntingtin into cells expressing functional NMDA receptors induces a selective augmentation of receptor current in receptors containing the NR2B subunit (Chen et al., 1999). Both NR2A and NR2B subunits are expressed in the hippocampus, and it is possible that the difference seen between the R6/2 and $Y A C$ mouse lines may reflect a differential distribution of receptor subunits. Alternatively, NMDA receptor augmentation may represent a gain of function attributable to the C-terminal portion of mutant huntingtin (Chen et al., 1999), a portion of the protein that is absent in the R6/2 mouse.

Activation of NMDA receptors appears to be an essential component of the synaptic dysfunction reported here, with changes in both PTP and LTD requiring functional NMDA receptors. Receptor expression and binding profiles in striatum and neocortex of the R6/2 mouse show normal expression of NMDA receptors but a marked decrease in dopaminergic and certain subunits of metabotropic glutamate receptors (Cha et al., 1998). Similar receptor changes in the hippocampus might pro- 


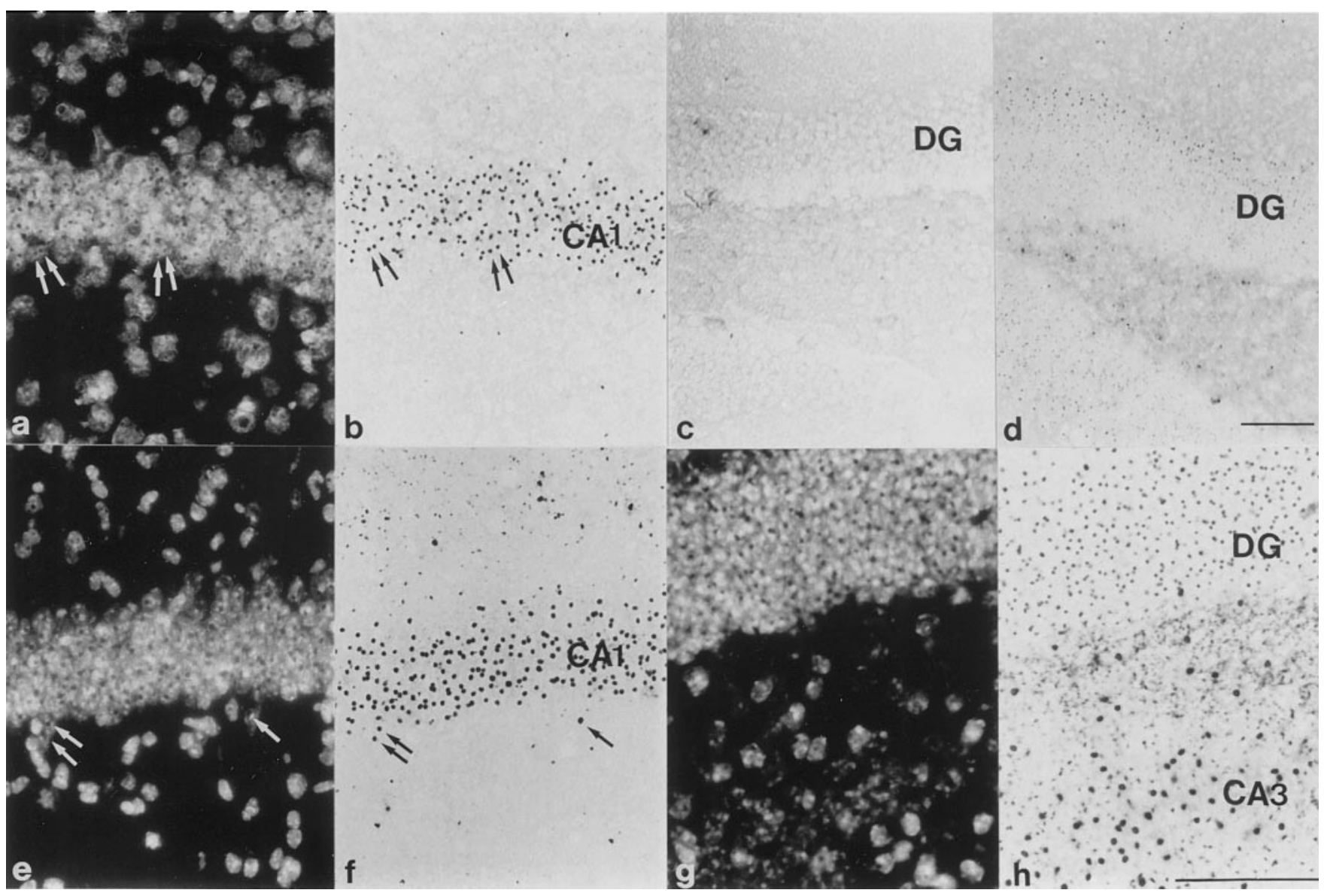

Figure 5. The temporal and regional pattern of NII distribution in HD mouse hippocampus. Ubiquitinated inclusions are seen in CA1 pyramidal neurons $(a, b, e, f)$ and granule cells of the dentate gyrus $(D G)(c, d, g, h)$ in hippocampi of mice killed at 3 weeks $(a, b, d), 7$ weeks $(c)$, or 10 weeks $(e, f, g, h)$ of age. Nuclei in $b, f$, and $h$ were visualized by staining with Hoechst $33258(a, e, g)$. Inclusions are clearly localized to the nuclei of CA1 pyramidal cells (arrows in $a, b, e, f)$ and dentate gyrus $(g, h)$. Inclusions are present in CA1 neurons, but not granule cells, at 3 weeks of age. Some inclusions can been seen in the dentate gyrus at 7 weeks but are not present throughout the stratum granulosum until 10 weeks of age. Scale bars (shown in $d$ ): $a-f, 100 \mu \mathrm{m}$; (shown in $h$ ): $g, h, 100 \mu \mathrm{m}$.

vide an explanation for impaired LTP and the novel LTD reported here. Under certain conditions, the induction of LTP depends critically on activation of postsynaptic metabotropic glutamate receptors (Bortolotto et al., 1994). Furthermore, presynaptic metabotropic receptors mediate increases in transmitter release associated with both the induction and maintenance of LTP (Herrero et al., 1992; Sanchezprieto et al., 1996). A reduction in receptor number would be expected to raise the inductive threshold for LTP, a view consistent with the data presented here. Dopaminergic receptors are also involved in the induction (Blitzer et al., 1995) and maintenance (Frey et al., 1991, 1993) of LTP, via cAMP activation of protein kinase A (PKA). The role of PKA during LTP induction is to maintain the inactivation of protein phosphatases (Blitzer et al., 1995) that otherwise would facilitate the induction of LTD (Mulkey et al., 1993). If phosphatase inactivation is compromised by a reduced number of dopaminergic receptors, then one would expect an impairment in LTP similar to that reported here. Furthermore, such an impairment would have a postsynaptic locus and therefore could not be explained by dysfunctional transmitter release as proposed for the $H d h$ mutant. Moreover, an inappropriate pattern of phosphatase activation might also account for the NMDA receptor-dependent form of LTD expressed at R6/2 synapses.

It has been reported that $\mathrm{R} 6 / 2$ mice exhibit a progressive form of diabetes (Hurlbert et al., 1999). Moderate cognitive impairment is a complication of diabetes in man (Franceschi et al., 1984). Furthermore, poor spatial cognition and impaired LTP have also been reported in rats with streptozotocin-induced diabetes (Biessels et al., 1998). However, we are confident that the changes in cognition and plasticity reported here are not directly attributable to diabetes. First, blood samples taken from (nonfasted) animals used in the preparation of slices for this study, at a time when changes in synaptic plasticity at CA1 synapses were fully manifest (4-7 weeks of age), had blood glucose levels within the normal range: $4.2 \pm 0.7 \mathrm{~mm}(n=7)$ and $6.0 \pm 0.3 \mathrm{~mm}(n=$ 5 ) for transgenic and control mice, respectively. Second, we did not see a change in maximal synaptic responses, unlike diabetic rats, which show a marked decrease (Chabot et al., 1997).

The role of aggregate formation in the pathology of HD is widely debated, with proposed roles ranging from the benign to the benevolent or the malevolent (Saudou et al., 1998; Gutekunst et al., 1999; Scherzinger et al., 1999). Inclusions have now been reported in several transgenic mouse models (Davies et al., 1997; Reddy et al., 1998; Hodgson et al., 1999; Schilling et al., 1999), with the notable exception of the $H d h$ mutant (Shelbourne et al., 1999). In the R6/2 mouse, the presentation of an overt phenotype follows the appearance of NIIs detected using antibodies to ubiquitin. Furthermore, manipulations that delay the appearance 
Figure 6. Age- and region-dependent changes in plasticity in the HD mouse. $a$, Left, The magnitude of LTP expressed at transgenic CA1 synapses over three age ranges is compared with that seen in the control slices. LTP is significantly impaired in transgenic slices from 5 weeks onward [5-6 weeks, $26.2 \pm 3.9 \%$ $(n=5) ; 7-9$ weeks, $30.9 \pm 7.2 \%(n=5) ; \geq 10$ weeks, $22.9 \pm 4.54(n=7)$; controls slices, $56.5 \pm 6.6 \%(n=$ 13); level of significance determined using Bonferroni multiple comparisons test]. Right, Lasting activitydependent synaptic depression is enhanced in transgenic slices from 5 weeks onward [5-6 weeks, $-38.8 \pm$ $5.5 \%(n=5) ; 7-9$ weeks, $-47.4 \pm 11.4 \%(n=5) ; \geq 10$ weeks, $-51.6 \pm 4.2 \%(n=8)$; control slices, $-7.0 \pm$ 2.9]. $b$, The induction of LTP at granule cell synapses is age-dependent in transgenic mice. Top, LTP was induced in both control and transgenic slices in animals aged $4-7$ weeks $[57.8 \pm 15.7 \%(n=8)$ and $30.0 \pm 9.4 \%(n=11)$, respectively; $p<0.05]$. Bottom, LTP is absent at transgenic granule cell synapses in animals aged $\geq 12$ weeks $[68.2 \pm 13.4 \%(n=5)$ and $15.8 \pm 5.4 \%(n=7)$ in control and transgenic slices, respectively; $p<0.01]$. $c$, The induction of LTD at transgenic CA1 synapses is NMDA receptordependent. Low-frequency conditioning (open bar) failed to induce LTD in the presence of $25 \mu \mathrm{M}$ D-AP5 ( filled bar) $(1.8 \pm 0.1 \%, 3$ slices from 3 animals; measured $1 \mathrm{hr}$ after conditioning). Subsequent low-frequency conditioning after washout of AP5 successfully induced LTD ( $-31.8 \pm 0.2 \% ; p<0.01$, paired $t$ test).

of the phenotype, such as the inhibition of the apoptotic protease caspase-1, also delay the appearance of the inclusions (Ona et al., 1999). The relationship between the appearance of NIIs in the R6/2 hippocampus and alterations in synaptic plasticity suggests that cells in which inclusions are present are dysfunctional. However, a causal relationship has not been established, and it should be noted that the $H d h$ mouse, which exhibits a form of impaired LTP, does not develop inclusions (Shelbourne et al., 1999).

The R6/2 mouse provides us with a useful tool to study changes in cognitive and synaptic function related to HD. In particular, the selective vulnerability of CA1 synapses provides us with a model for investigating dysfunctional synaptic transmission that may underlie the cognitive deficit seen in presymptomatic HD.

\section{REFERENCES}

Becher MW, Kotzuk JA, Sharp AH, Davies SW, Bates GP, Price DL, Ross CA (1998) Intranuclear neuronal inclusions in Huntington's disease and dentatorubral and Pallidoluysian atrophy: correlation between the density of inclusions and IT15 CAG triplet repeat length. Neurobiol Dis 4:387-397.

Biessels G-J, Kamal A, Urban IJA, Spruijt BM, Erkelens DW, Gispen WH (1998) Water maze learning and hippocampal synaptic plasticity in streptozotocin-diabetic rats: effects of insulin treatment. Brain Res 800:125-135.

Bliss TVP, Collingridge GL (1993) A synaptic model of memory: longterm potentiation in the hippocampus. Nature 361:31-39.

Blitzer RD, Wong T, Nouranifar R, Iyengar R, Landau EM (1995) Postsynaptic cAMP pathway gates early LTP in hippocampal CA1 region. Neuron 15:1403-1414.

Bortolotto ZA, Bashir ZI, Davies CH, Collingridge GL (1994) A molecular switch activated by metabotropic glutamate receptors regulates induction of long-term potentiation. Nature 368:740-743.

Carter RJ, Lione LA, Humby T, Mangiarini L, Mahal A, Bates GP, Dunnett SB, Morton AJ (1999) Characterization of progressive motor deficits in mice transgenic for the human Huntington's disease mutation. J Neurosci 19:3248-3257.

Cha JHJ, Kosinski CM, Kerner JA, Alsdorf SA, Mangiarini L, Davies SW, Penney JB, Bates GP, Young AB (1998) Altered brain neurotransmitter receptors in transgenic mice expressing a portion of an abnormal human Huntington disease gene. Proc Natl Acad Sci USA 95:6480-6485.

Chabot C, Massicotte G, Milot M, Trudeau F, Gagne J (1997) Impaired modulation of AMPA receptors by calcium-dependent processes in streptozotocin-induced diabetic rats. Brain Res 768:249-256.

Chapman PF, White GL, Jones MW, Cooper Blacketer D, Marshall VJ, Irizarry M, Younkin L, Good MA, Bliss TV, Hyman BT, Younkin SG, Hsiao KK (1999) Impaired synaptic plasticity and learning in aged amyloid precursor protein transgenic mice. Nat Neurosci 2:271-276.

Chen NS, Luo T, Wellington C, Metzler M, McCutcheon K, Hayden MR, Raymond LA (1999) Subtype-specific enhancement of NMDA receptor currents by mutant Huntingtin. J Neurochem 72:1890-1898.

Cochilla AJ, Alford S (1999) NMDA receptor-mediated control of presynaptic calcium and neurotransmitter release. J Neurosci 19:193-205.

Collingridge GL, Kehl SJ, McLennan H (1983) Excitatory amino acids in synaptic transmission in the Schaffer collateral-commissural pathway of the rat hippocampus. J Physiol (Lond) 334:33-46.

Davies SW, Turmaine M, Cozens BA, Raza AS, Mahal A, Mangiarini L, Bates GP (1999) From neuronal inclusions to neurodegeneration: neuropathological investigation of a transgenic mouse model of Huntington's disease. Philos Trans R Soc Lond B Biol Sci 354:971-979.

Davies SW, Turmaine M, Cozens BA, DiFiglia M, Sharp AH, Ross CA, Scherzinger E, Wanker EE, Mangiarini L, Bates GP (1997) Formation of neuronal intranuclear inclusions underlies the neurological dysfunction in mice transgenic for the HD mutation. Cell 90:537-548.

DiFiglia M, Sapp E, Chase K, Schwarz C, Meloni A, Young C, Martin E, Vonsattel JP, Carraway R, Reeves SA, Boye FM, Aronin N (1995) Huntingtin is a cytoplasmic protein associated with vesicles in human and rat brain neurons. Neuron 14:1075-1081.

DiFiglia M, Sapp E, Chase KO, Davies SW, Bates GP, Vonsattel JP, Aronin N (1997) Aggregation of huntingtin in neuronal intranuclear inclusions and dystrophic neurites in brain. Science 277:1990-1993.

Dudek SM, Bear MF (1992) Homosynaptic long-term depression and effects of $N$-Methyl-D-aspartate receptor blockade. Proc Natl Acad Sci USA 89:4363-4367.

Folstein SE (1990) Huntington's disease. Baltimore: John Hopkins University.

Foroud T, Siemers E, Kleindorfer D, Bill DJ, Hodes ME, Norton JA, Conneally PM, Christian JC (1995) Cognitive scores in carriers of Huntington's Disease gene compared to noncarriers. Ann Neurol 37:657-664.

Franceschi M, Cecchetto R, Minicucci F, Smizne S, Baio G, Canal N (1984) Cognitive processes in insulin-dependent diabetes. Diabetes Care 7:228-231.

Frey U, Huang YY, Kandel ER (1993) Effects of cAMP simulate a late stage of LTP in hippocampal CA1 neurons. Science 260:1661-1664.

Frey U, Matthies H, Reymann KG, Matthies H (1991) The effect of dopaminergic D1-receptor blockade during tetanization on the expres- 
sion of long-term potentiation in the rat CA1 region in vitro. Neurosci Lett 129:111-114.

Gustafsson B, Wigstrom H, Abraham WC, Huang YY (1987) Long-term potentiation in the hippocampus using depolarizing current pulses as the conditioning stimulus to single volley synaptic potentials. J Neurosci $7: 774-780$.

Gutekunst CA, Levey AI, Heilman CJ, Whaley WL, Yi H, Nash NR, Rees HD, Madden JJ, Hersch SM (1995) Identification and localization of huntingtin in brain and human lymphoblastoid cell lines with anti-f usion protein antibodies. Proc Natl Acad Sci USA 92:8710-8714.

Gutekunst CA, Li SH, Yi H, Mulroy JS, Kuemmerle S, Jones R, Rye D, Ferrante RJ, Hersch SM, Li XJ (1999) Nuclear and neuropil aggregates in Huntington's disease: relationship to neuropathology. J Neurosci 19:2522-2534.

Hanse E, Gustafsson B (1992) Long-term potentiation and field epsps in the lateral and medial perforant paths in the dentate gyrus in vitro: a comparison. Eur J Neurosci 4:1191-1201.

Harper PS (1996) Huntington's disease. Major problems in neurology, Vol 31, Ed 2. Philadelphia: W. B. Saunders.

Hedreen JC, Peyser CE, Folstein SE, Ross CA (1991) Neuronal loss in layers V and VI of cerebral cortex in Huntington's disease. Neurosci Lett 133:257-261.

Herrero I, Miras-Portugal MT, Sanchez-Prieto J (1992) Positive feedback of glutamate exocytosis by metabotropic presynaptic receptor stimulation. Nature 360:163-166.

Hodgson JG, Agopyan N, Gutekunst C-A, Leavitt BR, LePaine F, Singaraja R, Smith DJ, Bissada N, McCutcheon K, Nasir J, Jamot L, Li X-J, Stevens ME, Rosemond E, Rader JC, Phillips AG, Rubin EM, Hersch SM, Hayden MR (1999) A YAC mouse model for Huntington's disease with full-length mutant huntingtin, cytoplasmic toxicity, and selective striatal neurodegeneration. Neuron 23:181-192.

Hurlbert MS, Zhou W, Wasmeier C, Kaddis FG, Hutton JC, Freed CR (1999) Mice transgenic for an expanded CAG repeat in the Huntington's disease gene develop diabetes. Diabetes 48:649-651.

Jenkins B, Koroshetz W, Beal M, Rosen B (1993) Evidence for impairment of energy metabolism in vivo in Huntington's disease using localized 1H NMR spectroscopy. Neurology 43:2689-2695.

Lange KW, Sahakian BJ, Quinn NP, Marsden CD, Robbins TW (1995) Comparison of executive and visuospatial memory function in Huntingtons disease and dementia of Alzheimer-type matched for degree of dementia. J Neurol Neurosurg Psychiatry 58:598-606.

Lawrence AD, Hodges JR, Rosser AE, Kershaw A, Ffrench-Constant C, Rubinsztein DC, Robbins TW, Sahakian BJ (1998) Evidence for specific cognitive deficits in preclinical Huntington's disease. Brain 121:1329-1341.

Lawrence AD, Sahakian BJ, Hodges JR, Rosser AE, Lange KW, Robbins TW (1996) Executive and mnemonic functions in early Huntington's disease. Brain 119:1633-1645.

Levine MS, Klapstein GJ, Koppel A, Gruen E, Cepeda C, Vargus ME, Jokel ES, Carpenter EM, Zanjani H, Hurst RS, Efstratiadis A, Zeitlin S, Chesselet M-F (1999) Enhanced sensitivity to $N$-methyl-D-aspartate receptor activation in transgenic and knockin mouse models of Huntington's disease. J Neurosci Res 58:515-532.

Lione LA, Carter RJ, Hunt MJ, Bates GP, Morton AJ, Dunnett SB (1999) Selective discrimination learning impairments in mice expressing the human Huntington's disease mutation. J Neurosci 19:10428-10437.

Mangiarini L, Sathasivam K, Seller M, Cozens B, Harper A, Hetherington C, Lawton M, Trottier Y, Lehrach H, Davies SW, Bates GP (1996) Exon 1 of the HD gene with an expanded CAG repeat is sufficient to cause a progressive neurological phenotype in transgenic mice. Cell 87:493-506.

Mohr E, Brouwers P, Claus JJ, Mann UM, Fedio P, Chase TN (1991) Visuospatial cognition in Huntingtons disease. Mov Disord 6:127-132.

Morris R, Anderson E, Lynch GS, Baudry M (1986) Selective impairment of learning and blockade of long-term potentiation by an $N$-methyl-D-aspartate receptor antagonist, AP5. Nature 319:774-776.

Moser EI, Krobert KA, Moser MB, Morris RG (1998) Impaired spatial learning after saturation of long-term potentiation. Science 281:2038-2042.

Mulkey RM, Herron CE, Malenka RC (1993) An essential role for protein phosphatases in hippocampal long-term depression. Science 261:1051-1055.
Murphy KPSJ, Williams JH, Bettache N, Bliss TVP (1994) Photolytic release of nitric oxide modulates NMDA receptor transmission but does not induce long-term potentiation. Neuropharmacology 33:13751385.

Murphy KPSJ, Bliss TVP (1999) Photolytically released nitric oxide produces a delayed but persistent suppression of LTP in area CA1 of the rat hippocampal slice. J Physiol (Lond) 515:453-462.

Nalbantogluet J, Tirado Santiago G, Lahsaini A, Poirier J, Goncalves O, Verge G, Momoli F, Welner SA, Massicotte G, Julien JP, Shapiro ML (1997) Impaired learning and LTP in mice expressing the carboxy terminus of the Alzheimer amyloid precursor protein. Nature 387:500-505.

Nosten-Bertrand M, Errington ML, Murphy KPSJ, Tokugawa Y, Barboni E, Kozlova E, Michalovich D, Morris RGM, Silver J, Stewart CL, Bliss TVP, Morris RJ (1996) Normal spatial learning despite regional inhibition of LTP in mice lacking Thy-1. Nature 379:826-829.

Ona V, Li MW, Vonsattel J, Andrews L, Khan S, Chung W, Frey A, Menon A, Li X, Stieg P, Yuan J, Penney J, Young AB, Cha JH, Friedlander RM (1999) Inhibition of caspase-1 slows disease progression in a mouse model of Huntington's disease. Nature 399:263-267.

Paulson HL, Fischbeck KH (1996) Trinucleotide repeats in neurogenetic disorders. Annu Rev Neurosci 19:79-107.

Perutz M (1999) Glutamine repeats and neurodegenerative diseases: molecular aspects. Trends Biochem Sci 24:58-63.

Reddy PH, Williams M, Charles V, Garrett L, Pike Buchanan L, Whetsell Jr WO, Miller G, Tagle DA (1998) Behavioural abnormalities and selective neuronal loss in HD transgenic mice expressing mutated full-length HD cDNA. Nat Genet 20:198-202.

Reynolds DS, Carter RJ, Morton AJ (1998) Dopamine modulates the susceptibility of striatal neurons to 3-nitropropionic acid the rat model of Huntington's disease. J Neurosci 18:10116-10127.

Sanchezprieto J, Budd DC, Herrero I, Vazquez E, Nicholls DG (1996) Presynaptic receptors and the control of glutamate exocytosis. Trends Neurosci 19:235-239.

Saudou F, Finkbeiner S, Devys D, Greenberg ME (1998) Huntingtin acts in the nucleus to induce apoptosis but death does not correlate with the formation of intranuclear inclusions. Cell 95:55-66.

Scherzinger E, Sittler A, Schweiger K, Heiser V, Lurz R, Hasenbank R, Bates GP, Lehrach H, Wanker EE (1999) Self-assembly of polyglutamine-containing huntingtin fragments into amyloid-like fibrils: implications for Huntington's disease pathology. Proc Natl Acad Sci USA 96:4604-4609.

Schilling G, Becher MW, Sharp AH, Jinnah HA, Duan K, Kotsuk JA, Slunt HH, Ratovitski T, Cooper JK, Jenkins NA, Copeland NG, Price DL, Ross CA, Borchelt DR (1999) Intranuclear inclusions and neuritic aggregates in transgenic mice expressing a mutant N-terminal fragment of huntingtin. Hum Mol Genet 8:397-407.

Sharp AH, Loev SJ, Schilling G, Li SH, Li XJ, Bao J, Wagster MV, Kotzuk JA, Steiner JP, Lo A (1995) Widespread expression of Huntington's disease gene (IT15) protein product. Neuron 14:1065-1074.

Shelbourne PF, Killeen N, Hevner RF, Johnston HM, Tecott L, Lewandoski M, Ennis M, Ramirez L, Li Z, Iannicola C, Littman DR, Myers RM (1999) A Huntington's disease CAG expansion at the murine Hdh locus is unstable and associated with behavioural abnormalities in mice. Hum Mol Genet 8:763-774.

Spargo E, Everall IP, Lantos PL (1993) Neuronal loss in the hippocampus in Huntington's disease: a comparison with HIV infection. J Neurol Neurosurg Psychiatry 56:487-491.

Stewart CA, Morris RGM (1993) The watermaze. In: Behavioural neuroscience: a practical approach (Shagal A, ed), pp 107-122. Oxford: IRL.

Usdin MT, Shelbourne PF, Myers RM, Madison DV (1999) Impaired synaptic plasticity in mice carrying the Huntington's disease mutation. Hum Mol Genet 8:839-846.

Utal AK, Stopka AL, Roy M, Coleman PD (1998) PEP-19 immunohistochemistry defines the basal ganglia and associated structures in the adult human brain, and is dramatically reduced in Huntington's disease. Neuroscience 86:1055-1063.

Vonsattel JP, Myers RH, Stevens TJ, Ferrante RJ, Bird ED, Richardson EP (1985) Neuropathological classification of Huntington's Disease. J Neuropathol Exp Neurol 44:559-577. 